\title{
Infecção natural por Trypanosoma evansi em cães
}

\author{
Natural infection by Trypanosoma evansi in dogs
}

\author{
Cristina Braccini Colpo $^{1}$ Silvia Gonzalez Monteiro ${ }^{2}$ Daniel Roulim Stainki ${ }^{3}$ \\ Elida Teresita Braccini Colpo ${ }^{4}$ Graciela Braccini Henriques ${ }^{4}$
}

\begin{abstract}
O presente trabalho relata duas infecções naturais por Trypanosoma evansi em cães, que vieram a óbito no município de Uruguaiana, RS. Os animais oriundos da zona rural foram recebidos no hospital veterinário da Pontifícia Universidade Católica do Rio Grande do Sul (PUCRS), em diferentes datas, apresentando apatia, febre e aumento dos linfonodos submandibulares. No esfregaço sangüíneo, foram identificadas formas flageladas pertencentes à espécie $\boldsymbol{T}$. evansi. A verificação desses casos serve de alerta aos proprietários de animais e médicos veterinários para a presença da doença na região e salienta a necessidade de maiores investigações na epidemiologia da parasitose $e$ criação de medidas profiláticas que evitem novas infecções.
\end{abstract}

Palavras-chave: Trypanosoma evansi, cães, infecção natural, Mastigophora, Rio Grande do Sul.

\section{ABSTRACT}

The present paper describes cases of natural infection by Trypanosoma evansi in dogs that eventually died in Uruguaiana, in the southern Brazilian state of Rio Grande do Sul, Brazil. The animals from the rural zone were admitted to the Pontifícia Universidade Católica do Rio Grande do Sul (PUC-RS) Veterinary Hospital presenting the following clinical signs: apathy, fever and enlargement of the submandibular lymphonodes. Flagellated forms in the blood films were identified as belonging to the species T. evansi. The discovery of these cases raises an allert to the presence of the disease in the area, emphasizing the need for further investigation of the epidemiology of the infection and also the study of prophylathic measures to prevent new cases.
Key words: Trypanosoma evansi, dogs, natural infection, Mastigophora, Rio Grande do Sul State, Brazil.

Trypanosoma evansi é um protozoário, da classe Mastigophora, cuja transmissão é essencialmente mecânica, pois ele é transferido de um hospedeiro mamífero a outro pela alimentação interrompida de insetos picadores, principalmente tabanídeos e Stomoxys sp. Esta espécie é encontrada parasitando animais domésticos em algumas regiões do Brasil como o Pantanal Sul Matogrossense, onde sua incidência assume um caráter endêmico e acomete principalmente os cavalos (BRANDÃO et al., 2002).

A fase aguda da doença caracteriza-se pelo surgimento de febre intermitente, edema subcutâneo, anemia progressiva, cegueira, letargia e alterações hemostáticas. Durante a fase subaguda, há a resolução dos sinais clínicos, o que faz com que, muitas vezes, a doença não seja identificada ao exame clínico menos atento, sendo diagnosticada apenas na fase crônica com a piora do estado geral do animal e agravamento dos sintomas (BRANDÃO et al., 2002).

No dia 13 de fevereiro de 2002, foi recebido no hospital Veterinário da PUCRS - Campus Uruguaiana, um cão da raça Rotweiller de quatro anos, pesando 45kg, oriundo da zona rural do município. O mesmo apresentava emagrecimento, salivação e cansaço. No exame clínico, a

${ }^{1}$ Médico Veterinário autônomo, Brasil.

${ }^{2}$ Professor Adjunto de Parasitologia Veterinária da Universidade Federal de Santa Maria (UFSM). Faixa de Camobi, Km 9 prédio 20, sala 4232, 97105900, Santa Maria, RS, Brasil. E-mail: sgmonteiro@uol.com.br. Autor para correspondência.

${ }^{3}$ Professor adjunto de Cirurgia Veterinária da Pontifícia Universidade Católica do Rio Grande do Sul (PUCRS), Campus Uruguaiana, Brasil.

${ }^{4}$ Médico Veterinário da PUCRS Campus Uruguaiana, Brasil. 
temperatura estava em $40^{\circ} \mathrm{C}$, mucosas pouco rosadas, linfonodos poplíteos aumentados, secreção ocular, salivação e estertor pulmonar unilateral. Foi realizado hemograma, bioquímica sangüínea(Tabela 1) e administrado o tratamento baseado na anemia apresentada, com imunoestimulante, antibiótico e suplemento a base de ferro. Após seis dias, o animal retornou ao hospital apresentando edema nas patas e focinho, respiração ofegante, temperatura de $39^{\circ} \mathrm{C}$, sendo que a secreção ocular e salivação persistiam e o estertor pulmonar apresentava-se bilateral, porém o mesmo alimentava-se normalmente e bebia água em excesso.

Quinze dias após a segunda consulta, o animal retornou bastante apático, pesando 35kg, com temperatura de $40,3^{\circ} \mathrm{C}$, urinando em jato (com presença de espuma), desidratado, com mucosas pálidas, apresentando vômito e sem alimentar-se há dois dias. Foi realizado hemograma e bioquímica sangüínea (Tabela 1). Com base nos resultados dos exames, chegou-se ao diagnóstico presuntivo de glomerulonefrite. Após três meses de tratamento, o animal morreu, não se chegando a provável causa de tal distúrbio renal. Alguns meses mais tarde, ao observar-se novamente o esfregaço sangüíneo do animal identificaram-se estruturas semelhantes a hemoparasitas que foram fotografados e submetidos a análises.

No dia 12 de maio de 2004, um cão da raça Labrador de oito anos de idade, macho, pesando 30kg e oriundo da zona rural do município chegou ao hospital veterinário da PUCRS em estado agônico. Segundo o proprietário, o animal já não se alimentava bem nas últimas semanas e nos últimos 5 dias permanecia somente em decúbito. Ao exame clínico, a temperatura era de $39,2^{\circ} \mathrm{C}$, apresentava hálito urêmico, estava desidratado com estertor pulmonar e mucosas pálidas. Foi realizado hemograma, e no esfregaço sangüíneo, visualizou-se em média 30 formas flageladas por campo microscópico pertencentes ao gênero Trypanosoma e no exame bioquímico de creatinina, observou-se a concentração de $18 \mathrm{mg} \mathrm{dl}^{-1}$ conforme demonstrado na tabela 1. Foi administrado aceturato de diminazeno na dose de 3,5mg kg-1 via IM, ampicilina benzatina e sódica, fluidoterapia e metoclopramida porém o animal morreu na mesma noite.

Os parasitos encontrados nos cães foram identificados morfologicamente e biometricamente como Trypanosoma (Trypanozoon) evansi (Steel, 1885) Balbiani, 1888 conforme relatos de SILVA et al. (2002) e RAMIREZ et al. (1997) (Figura 1), parasita este, segundo relatos de BRANDÃO et al. (2002) causador de glomerulonefrite, quadro clínico apresentado pelos animais.

Os sinais clínicos descritos por BRANDÃO et al. (2002) e já citados neste trabalho, sugerem que os cães encontravam-se na fase crônica da doença, levando-os ao comprometimento renal irreversível o que causou a sua morte. A mesma citação relata que a presença do parasito na circulação induz à produção de imunoglobulinas, que podem se depositar na camada basal glomerular, causando redução da taxa de filtração glomerular. Estas alterações foram observadas nos dois casos e comprovadas através do exame bioquímico de creatinina juntamente com o hálito urêmico, presente somente no cão Labrador. AQUINO et al. (1999), ao infectarem artificialmente cães com T. evansi, também relataram achados clínicos como edema, febre, membranas mucosas pálidas e aumento dos linfonodos, descritos no presente trabalho.

Apesar de SILVA et al. (2002) recomendarem para tratamento de $T$. evansi a dosagem de 7,0 mg/kg de aceturato de diminazeno, no cão labrador foi utilizada uma dosagem de 3,5

Tabela 1 - Resultados dos exames laboratoriais dos cães infectados naturalmente por $\boldsymbol{T}$. evansi no município de Uruguaiana.

\begin{tabular}{|c|c|c|c|c|}
\hline \multirow{2}{*}{ Parâmetros } & \multicolumn{2}{|c|}{ Rotweiller } & \multirow{2}{*}{$\frac{\text { Labrador }}{\text { Dia 12/05/04 }}$} & \multirow{2}{*}{ Valores de referência**** } \\
\hline & Dia 13/02/02 & Dia 05/03/02 & & \\
\hline Hemácias milhões $/ \mathrm{mm}^{3}$ & 4,9 & 5,7 & 2,7 & 6,2 a 8,7 \\
\hline Hematócrito (\%) & 32 & 32 & 18 & 43,3 a 59,3 \\
\hline Hemoglobina (g/dL) & 12 & 10 & 5,3 & 14,1 a 20 \\
\hline VCM (fL)* & 65 & 66 & 66,6 & 63 а 77,1 \\
\hline CHCM $(\%)^{* *}$ & 37 & 26 & 29,4 & 29,9 a 35,6 \\
\hline Leucócitos & 8.900 & 16.000 & 7.600 & 6,0 a 16,0 \\
\hline Uréia (mg/dL) & - & 16,8 & & 7 a 32 \\
\hline Creatinina (mg/dL) & - & 4,9 & 18,1 & 0,5 a 1,4 \\
\hline FAS (UI/L)*** & - & 89,5 & & 0 a 90 \\
\hline
\end{tabular}

*Volume corpuscular médio,

**Índice médio da percentagem de hemoglobina por hemácia,

$* * *$ Fosfatase alcalina

****NAVARRO \& PACHALY, 1994 apud SILVA et al.(2002)

Ciência Rural, v.35, n.3, mai-jun, 2005. 


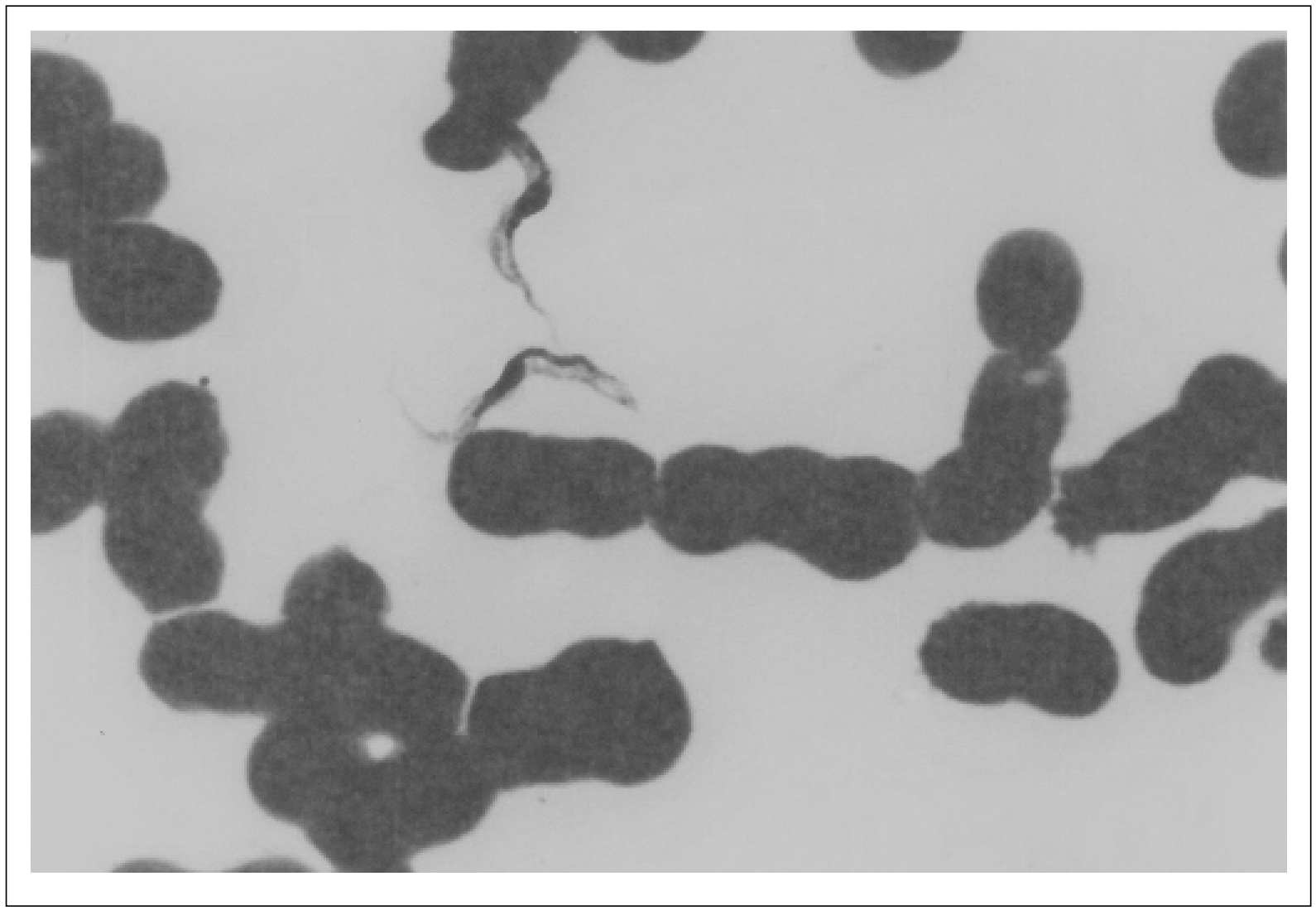

Figura 1 - Formas tripomastigotas de Trypanosoma evansi em esfregaço sanguíneo de cão

$\mathrm{mg} / \mathrm{kg}$ via IV já que a droga apresenta toxicidade (PESCADOR et al., 2003) o que pode, pelo estado de debilidade do animal, ter agravado o quadro clínico levando-o a óbito. Os reservatórios desse parasita foram estudados no Pantanal Sul-matogrossense sendo a positividade em $45 \%$ das capivaras examinadas daquela região (NUNEZ et al., 1993). Esse fato revela a necessidade de maiores estudos nos possíveis reservatórios do Rio Grande do Sul, pois há uma vasta população desse roedor no perímetro rural de Uruguaiana.

Os casos descritos são autóctones já que os animais nasceram no município e foram criados em fazendas da região. A falta de diagnóstico anterior deste parasito deve-se principalmente a pouca experiência dos profissionais e criadores sobre o parasito, já que este é o primeiro relato em cães no município. O presente trabalho relata a infecção natural por T. evansi em cães no Rio Grande do Sul, e sua ocorrência serve de alerta aos clínicos de pequenos animais da região, principalmente quando os caninos apresentam insuficiência renal, devendo-se incluí-lo dentro dos diagnósticos a serem diferenciados.

\section{REFERÊNCIAS BIBLIOGRÁFICAS}

AQUINO, L.P.C.T. et al. Clinical, parasitological and immunological aspects of experimental infection with Trypanosoma evansi in dogs. Mem Inst Oswaldo Cruz, Rio de Janeiro, v.94, n.2, p.255-260, 1999.

BRANDÃO, L.P. et. al. Natural infection by Trypanosoma evansi in dog - Case report. Clínica Veterinária, n.36, p.23-26, 2002.

NUNEZ, V.L.B. et al. Investigação epidemiológica sobre Trypanosoma (Trypanozoon) evansi no pantanal sul-matogrossense. Estudo de reservatórios. Rev Bras Parasitol Vet, v.2, n.1, p.41-44, 1993.

PESCADOR, C.A. et al. Intoxicação por aceturato de diminazeno em um canino: relato de caso. In: ENAPAVE - ENCONTRO NACIONAL DE PATOLOGIA VETERINÁRIA, 2003, Botucatu. Anais... SP, Botucatu : FMVZ, UNESP, 2003. p.62.

RAMIREZ, L. et al. Measurements of Trypanosoma evansi isolates from wild and domestic animals of the pantanal. Memórias do Instituto Oswaldo Cruz, Rio de Janeiro, v.92, p.483-484, 1997.

SILVA, R.A.M.S. et al. Trypanosoma evansi e Trypanosoma vivax: Biologia, Diagnóstico e controle. Corumbá : Embrapa Pantanal 2002. 141p.

Ciência Rural, v.35, n.3, mai-jun, 2005. 